\title{
A Literature Review on Intelligent Services Applied to Distance Learning
}

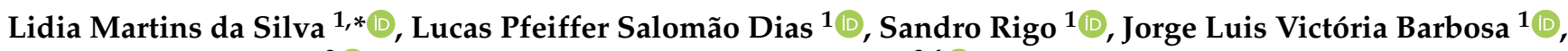 \\ Daiana R. F. Leithardt ${ }^{2}(\mathbb{D})$ and Valderi Reis Quietinho Leithardt ${ }^{3,4}(\mathbb{D}$
}

1 Applied Computing Graduate Program, University of Vale do Rio dos Sinos, Av. Unisinos 950, Bairro Cristo Rei, São Leopoldo 93022-750, Brazil; lucaspfsd@gmail.com (L.P.S.D.); rigo@unisinos.br (S.R.); jbarbosa@unisinos.br (J.L.V.B.)

2 Departamento de Química, Faculdade de Ciências, Universidade da Beira Interior, R. Marquês d'Ávila e Bolama, 6201-001 Covilhã, Portugal; daiana.leithardt@ubi.pt

3 COPELABS, Universidade Lusófona de Humanidades e Tecnologias,1749-024 Lisboa, Portugal; valderi@ipportalegre.pt

4 VALORIZA, Research Center for Endogenous Resources Valorization, Instituto Politécnico de Portalegre, 7300-555 Portalegre, Portugal

* Correspondence: lidiasilva@edu.unisinos.br

check for updates

Citation: da Silva, L.M.; Dias, L.P.S.; Rigo, S.; Barbosa, J.L.V.; Leithardt, D.R.F.; Leithardt, V.R.Q. A Literature Review on Intelligent Services

Applied to Distance Learning. Educ Sci. 2021, 11, 666. https://doi.org/ 10.3390/educsci11110666

Academic Editors: Enrique Barra

Arias, Aldo Gordillo and Sonsoles López-Pernas

Received: 10 September 2021

Accepted: 17 October 2021

Published: 21 October 2021

Publisher's Note: MDPI stays neutral with regard to jurisdictional claims in published maps and institutional affiliations.

Copyright: (c) 2021 by the authors. Licensee MDPI, Basel, Switzerland. This article is an open access article distributed under the terms and conditions of the Creative Commons Attribution (CC BY) license (https:/ / creativecommons.org/licenses/by/ $4.0 /)$.

\begin{abstract}
Distance learning has assumed a relevant role in the educational scenario. The use of Virtual Learning Environments contributes to obtaining a substantial amount of educational data. In this sense, the analyzed data generate knowledge used by institutions to assist managers and professors in strategic planning and teaching. The discovery of students' behaviors enables a wide variety of intelligent services for assisting in the learning process. This article presents a literature review in order to identify the intelligent services applied in distance learning. The research covers the period from January 2010 to May 2021. The initial search found 1316 articles, among which 51 were selected for further studies. Considering the selected articles, 33\% (17/51) focus on learning systems, 35\% (18/51) propose recommendation systems, 26\% (13/51) approach predictive systems or models, and $6 \%(3 / 51)$ use assessment tools. This review allowed for the observation that the principal services offered are recommendation systems and learning systems. In these services, the analysis of student profiles stands out to identify patterns of behavior, detect low performance, and identify probabilities of dropouts from courses.
\end{abstract}

Keywords: distance learning; intelligent services; literature review; virtual learning environments

\section{Introduction}

The emergence of the internet has facilitated access to information and the dissemination of knowledge through the distribution of educational materials. This scenario has boosted distance learning (DL), expanding its adoption in educational institutions around the world [1].

In the current circumstances in which the world faces the new coronavirus pandemic and adopts express guidelines from the World Health Organization (WHO) to follow social isolation protocols, DL is an ally in the teaching and learning process [2].

With the advance of the pandemic and the suspension of in-person classes, institutions, teachers, and students had to adapt their learning routine using distance learning to guarantee the continuity of the academic calendar and minimize the impact on education. The last decade has shown exponential growth in the adoption of e-learning due to the transaction from face-to-face classes to virtual classes [3].

Thus, education has sought a new meaning to its practices through the integrated use of multiple technologies in educational environments as resources for teaching-learning processes in the digital age. 
An educational environment is a space dedicated to learning, supporting pedagogical, psychological, and sociocultural conditions. The environment influences the development of the students' personality and creates conditions for the improvement of their skills. In addition, it reveals students' individual characteristics, interests, and talents. In addition, these environments ensure the interaction and cooperation of teachers and students [4]. This article considers educational environments at different levels of learning, focusing on intelligent services applied to distance learning.

Therefore, the pandemic scenario (COVID 19) intensifies the need to use distance learning as an element for the continuity of student education processes [5]. At the same time, the need for resources and tools that enable personalization, learning improvement, and the analysis of educational data is intensifying.

UNESCO has recommended these resources and tools since 2019 to meet the four challenges of the united nations for sustainable development Pedró et al. [6]. Digital mediation and its context in education are relevant assets for improving learning, inclusion, and equity, as it allows for an interaction process between teachers and students, as a coparticipation through a digital platform.

Distance learning allows for advancement in the educational system, overcoming the limitations of traditional fully face-to-face classes. It provides independence from the classroom, allowing students to freely choose the place and time of study, thus reaching a significant number of students with different socioeconomic profiles, which contributes to the democratization of learning.

The absence of a physical presence caused by remote access is one of the main problems faced by DL. This problem has been mitigated by Virtual Learning Environments (VLEs). VLEs have tools that allow and encourage contact between students and teachers. The use of discussion forums, debates, virtual meetings, and chats, among others, diversifies the teaching-learning routine and promotes interaction between them.

The growing search for information, high connectivity, and the use of virtual learning environments has generated a significant amount of data. These data can be analyzed, allowing for the discovery of student behavior. This analysis can be used to develop intelligent services dedicated to prediction and intervention in learning environments [7].

Becker et al. [8] argued that the mediation of learning is a trend, with an increasing amount of methods and tools used by teachers to assess, measure, and document students' academic life, learning advancement, skill attainment, and other educational needs. Becker et al. [8] also mentioned that the increase in adaptive learning technologies expands the amount of data that can be collected and analyzed. Learning Analytics (LA) is an alternative for the treatment and discovery of knowledge in databases generated by educational platforms [9].

Acatech [10] stated that the storage, analysis, and interpretation of data allow for the development of intelligent services, which can be customized according to the requirements of each user.

Koldewey et al. [11] claimed that intelligent services were first described by Allmendinger and Lombreglia [12]. The authors indicated that these services are data based, connected to intelligent objects, and allow for continuous and interactive feedback [13]. Furthermore, Beverungen et al. [14] stated that intelligent services are based on cocreation involving monitoring, optimization, control, and autonomous adaptation of results.

This article presents a study on intelligent services and how they are being applied to distance learning environments. The research covered the period from January 2010 to May 2021, considering five academic databases. The initial search returned the number of 1316 articles. After applying the exclusion criteria, 51 articles remained to be analyzed.

The article is divided into six sections. Following the Introduction, the second section addresses basic concepts that form the background of this study. The third defines the research methodology. Next, the article contains a section dedicated to the results, mainly presenting the types of intelligent services applied to distance learning. The fifth 
section contains a discussion of the results with 12 lessons learned. Finally, the last section addresses final considerations and future work.

\section{Background}

This section presents principles related to Distance Learning, Virtual Learning Environments, Intelligent Services, and Learning Analytics.

\subsection{Distance Learning}

Cambruzzi et al. [15] affirmed that the definitions of Distance Learning are diverse, but they all take into account these characteristics: (1) DL does not share the same physical spaces; (2 ) DL allows the students to study at different times; and (3) mediation is performed through technologies. Due to the high level of mediation, the DL generates data that can be used in different kinds of analysis [15].

Traxler [16] pointed out that the DL requires the autonomy of the student, and if associated with the use of information technology, it promotes knowledge quickly and widely, stimulating the student to search for new knowledge.

\subsection{Virtual Learning Environments}

When dealing with distance learning, it is worth highlighting the use of environments that support the educational processes. VLEs allow for the sharing of contexts during the development of activities. Furthermore, it allows the synchronous and asynchronous communication between people in learning environments [9].

Waheed et al. [7] defined VLE as a computational software that aggregates different media and resources, allowing the propagation of information. It enables data storage, retrieval, and distribution, as well as synchronous and asynchronous bidirectional communication, contributing to the generation of digital data that can be used to assess students.

According to Clow [17], there is a large amount of data available about users, due to the increased use of online learning environments. In this sense, the growing use of VLEs provides the tools to develop learning patterns adaptable to the user's profile [18].

\subsection{Intelligent Services}

According to Cummaudo et al. [19] and Hosseini et al. [20], the development of intelligent services differs from the usual web services, as they are developed with components based on artificial intelligence (AI).

The predictions performed by the intelligent services focus only on training datasets, and the results obtained are presented as probabilities that the inference satisfies one or more labels in the training data [19].

According to Cummaudo et al. [19] due to the evolution of intelligent services, training datasets must be representative and frequently evaluated concerning the chosen service. These data allow for the continuous update of prediction algorithms.

Marquardt [21] defined an intelligent service as part of an intelligent task performed by a computer system, with behavior equivalent to that of a human being when performing a similar task.

The Smart Urban Services project defined intelligent services as services adapted to specific use cases of customers with the help of data and intelligent processing [22], and according to Koldewey et al. [23], intelligent services allow a company to become competitive and innovative.

\subsection{Learning Analytics}

Learning Analytics (LA) refers to the application of analytical techniques to analyze educational data, such as data on student and teacher activities, the identification of behavior patterns, and the provision of information that can be used to improve learning [15].

According to Andrade et al. [9], LA is a rapidly growing field of research, focused on the development and application of processes and tools to collect, explore, and analyze 
large amounts of data. This analysis allows one to better understand the learning behavior of students, helping teachers to provide better support and appropriate interventions, and ultimately improve the quality of learning and teaching, as well as educational outcomes.

According to Waheed et al. [7], through learning analytics platforms, LA supports pedagogical strategies by offering real-time opinions and recommendations through learning analytics panels and VLE visualization systems. LA uses educational data and translates them into useful information for decision making, based on responses and records of students' academic life available on online learning platforms [7].

\section{Methodology}

This article carried out a study on intelligent services applied to distance learning from January 2010 to May 2021. The work used the following academic databases: ACM Digital Library (https:/ / dl.acm.org/ (accessed on 19 october 2021)) IEEE Xplore Digital Library (https:/ / ieeexplore.ieee.org/Xplore/home.jsp (accessed on 19 october 2021)), ScienceDirect (https:/ / www.sciencedirect.com / (accessed on 19 october 2021)), Springer Library (https: / /www.springer.com/br (accessed on 19 october 2021)) and Scopus (https:/ / www.scopus. $\mathrm{com} /$ home.uri (accessed on 19 october 2021)).

The search string considered the following keywords: Distance Learning, Learning Analytics, and Intelligent Services. In addition, these keywords allowed synonyms and related words to compose the search terms. The terms were joined through Boolean expressions and organized into three groups as presented in Table 1.

Table 1. Search string composition.

\begin{tabular}{cc}
\hline Major Terms & Search Terms \\
\hline Distance learning & (Distance learning OR e-learning OR educational technology OR online education OR virtual learning environment OR \\
& Distance learning OR learning management system) \\
\hline Learning Analytics & AND \\
\hline & (Learning Analytics OR data analysis OR academic data mining OR educational data mining OR learning data mining \\
OR data Science OR learning analytic OR school data mining)
\end{tabular}

The following inclusion criteria (IC) allowed the selection of articles: publication with full content; publications at journals, conferences, and workshops; works with data analysis applied to DL; works with intelligent services and publications from January 2010 to May 2021. On the other hand, the Exclusion Criteria (EC) were: publications that precede 2010; abstracts, books, dissertations, and theses; reviews and texts that use a language other than English; and works unrelated to this research and duplicate works.

The first step consisted in searching in the five databases and removing impurities, resulting in a total of 1316 articles, 271 in the ACM Digital Library database, 315 in the IEEE Xplore Digital Library, 188 in Science Direct, 289 in the Springer Library, and 253 in Scopus (Table 2). In the second step, the texts were filtered considering the title, abstract, and keywords. In this stage, 1036 articles were discarded, leaving 280 works that were revised through the introduction, results, and conclusions. The third step discharged 229 works, selecting 51 articles. The selected articles were fully read to ensure their suitability for this review study. 
Table 2. Number of articles obtained by database and selected in the study.

\begin{tabular}{ccccc}
\hline Database & Return Articles & Percentage Return Articles & Selected Articles & Percentage of Selected Articles \\
\hline ACM Digital Library & 271 & $21 \%$ & 17 & $33 \%$ \\
IEEE Xplore Digital Library & 315 & $24 \%$ & 10 & $20 \%$ \\
Science Direct & 188 & $14 \%$ & 4 & $8 \%$ \\
Springer Library & 289 & $22 \%$ & 13 & $25 \%$ \\
Scopus & 253 & $19 \%$ & 7 & $14 \%$ \\
\hline Total & $\mathbf{1 3 1 6}$ & $\mathbf{1 0 0} \%$ & $\mathbf{5 1}$ & $\mathbf{1 0 0} \%$ \\
\hline
\end{tabular}

\section{Results}

This section presents the types of intelligent services that are being offered in distance learning, according to this literature research. Among the intelligent services, the study found learning systems in 33\% (17/51) of the selected articles, recommendation systems in $35 \%(18 / 51)$, models or forecasting systems in $26 \%(13 / 51)$, and the assessment tools in $6 \%(3 / 51)$.

Table 3 shows the selected works with the authors, publication year, publication dataset, and a summary of the intelligent services. The following sections organize and discuss the articles as learning systems, recommendation systems, forecasting models or systems, and assessment tools.

\subsection{Learning Systems}

Lavoie and Proulx [24] developed a Learning Management System (LMS) with features oriented to flipped courses that allow students to watch videos and interact in Jupyter Notebooks. The LMS automatically creates progression graphs for students and sends automatic messages related to their progression. For instructors, the LMS automatically creates statistics on overall class and exercise progression. This allows teachers to target students with difficulty who can be helped individually, decreasing the failure rate.

Dahdouh et al. [25] developed an online learning system based on big data technologies and cloud computing. The authors suggested a methodology to use the huge amount of data produced by online learning platforms. In addition, the authors proposed to develop a course recommendation system that helps students to select the most appropriate courses and guides them throughout the learning process.

Wang et al. [26] proposed a system that uses natural language processing (NLP) technology as a development and design tool. The assistant was built for online learning platforms to provide timely feedback to students and increase their enthusiasm for learning.

Kozierkiewicz-Hetmańska and Zyundefinedk [27] proposed a method to determine an opening learning scenario based on the ant colonies optimization technique. The algorithm tries to choose the learning material best suited to the learning styles and current level of knowledge stored in the student profile. The method for determining an initial learning scenario required defining a student profile and a representation of knowledge. According to the authors, the customization of the learning scenario is an important task in the design of intelligent tutorial systems, because research indicates that students achieve better learning outcomes if the teaching material is appropriate to their learning styles.

Table 3. List of articles containing intelligent services in distance learning.

\begin{tabular}{cccc}
\hline ID & Authors & Source & Summary \\
\hline 1 & Anaya et al. [28] & ACM & Recommendation system based on an ID in the context of collaborative learning in the \\
e-learning environment.
\end{tabular}


Table 3. Cont.

\begin{tabular}{|c|c|c|c|}
\hline ID & Authors & Source & Summary \\
\hline 6 & Dahdouh et al. [32] & Springer & Recommendation of courses to e-learning platforms. \\
\hline 7 & Dimopoulos et al. [33] & $\mathrm{ACM}$ & Moodle plug-in that implements an evaluation tool (Enriched Learning Analytic). \\
\hline 8 & El Fouki et al. [34] & $\mathrm{ACM}$ & System dedicated for assisting instructors on decision-making process. \\
\hline 9 & El Moustamid et al. [35] & $\mathrm{ACM}$ & $\begin{array}{l}\text { System that analyzes the student profiles indexing videos in order to offer students a } \\
\text { database with courses that correspond to their levels. }\end{array}$ \\
\hline 10 & Florian et al. [36] & Springer & System that supports indicators as learning analytical applications. \\
\hline 11 & Hamada [37] & ACM & $\begin{array}{l}\text { Model of an e-learning system based on Java2D technology and containing an } \\
\text { intensive set of learning materials to support all types of students. }\end{array}$ \\
\hline 12 & Huang et al. [38] & $\mathrm{ACM}$ & Deep Reinforcement learning structure for Exercise Recommendation. \\
\hline 13 & Iqbal et al. [39] & IEEE & $\begin{array}{l}\begin{array}{l}\text { Kernel Context Recommendation System algorithm, which is a flexible, fast } \\
\text { and accurate. }\end{array} \\
\text { a }\end{array}$ \\
\hline 14 & Joy et al. [40] & $\mathrm{ACM}$ & $\begin{array}{l}\text { Ontology model that encompasses the student profile and learning object attributes, } \\
\text { which can be used for recommending content on an e-learning platform. }\end{array}$ \\
\hline 15 & Kapembe and Quenum [41] & $\mathrm{ACM}$ & $\begin{array}{l}\text { System that conducts an hybrid recommendation through profiles students, the } \\
\text { relevance and quality of learning objects for the program in which the student is } \\
\text { enrolled, and student feedback. }\end{array}$ \\
\hline 16 & Kim and Kim [42] & IEEE & Personalized Tutor as a system that integrates three developmental learning networks. \\
\hline 17 & Kolekar et al. [43] & ScienceDirect & $\begin{array}{l}\text { Learning styles of students used to customization of user interface considering web } \\
\qquad \log \text { analysis. }\end{array}$ \\
\hline 18 & $\begin{array}{l}\text { Kozierkiewicz-Hetmańska and } \\
\text { Zyundefinedk [27] }\end{array}$ & Springer & $\begin{array}{l}\text { Algorithm to determine an opening learning scenario based on the ant colony } \\
\text { optimization technique. }\end{array}$ \\
\hline 19 & Lagman and Mansul [44] & ACM & $\begin{array}{l}\text { System to monitor paths of students in e-learning environments, allowing one to } \\
\text { determine difficult subjects and to provide academic intervention. }\end{array}$ \\
\hline 20 & Lavoie and Proulx [24] & $\mathrm{ACM}$ & Learning management system (LMS) oriented to inverted courses. \\
\hline 21 & Manhães et al. [45] & $\mathrm{ACM}$ & WAVE architecture that provides useful information about student performance. \\
\hline 22 & Sharma and Ahuja [46] & $\mathrm{ACM}$ & $\begin{array}{l}\text { Semantic recommendation using ontology to recommend relevant and personalized } \\
\text { learning content to students. }\end{array}$ \\
\hline 23 & Thai-Nghe et al. [47] & ScienceDirect & $\begin{array}{l}\text { Recommendation system techniques for mining educational data, especially to predict } \\
\text { student performance. }\end{array}$ \\
\hline 24 & Venugopalan et al. [48] & $\mathrm{ACM}$ & Content-based recommendation system. \\
\hline 25 & Wang et al. [26] & IEEE & $\begin{array}{l}\text { Intelligent teaching assistant system that replaces the way the user waits for } \\
\text { manual response. }\end{array}$ \\
\hline 26 & Zakrzewska [49] & $\mathrm{ACM}$ & $\begin{array}{l}\text { Agent-based recommendation system, which, for each new student, suggests a group } \\
\text { of students of similar profiles. }\end{array}$ \\
\hline 27 & Zaoudi and Belhadaoui [50] & $\mathrm{ACM}$ & $\begin{array}{l}\text { Learner Behavior Analytics model based on a system called Score and Behavior } \\
\text { Analytics to analyze student outcomes and behavior. }\end{array}$ \\
\hline 28 & Khosravi et al. [51] & $\mathrm{ACM}$ & $\begin{array}{l}\text { Adaptive learning system with a focus on the student, scalable, and independent of } \\
\text { content that depends on crowdsourcing and partnership with students for } \\
\text { the development. }\end{array}$ \\
\hline 29 & Zhang et al. [52] & SCOPUS & $\begin{array}{l}\text { Learning analysis using Moodle plugins to discover possibilities to improve the } \\
\text { learning process and reduce the number of under performing students. }\end{array}$ \\
\hline 30 & Angeline et al. [53] & SCOPUS & Discriminant analysis to measure student performance. \\
\hline 31 & Hashim et al. [54] & SCOPUS & $\begin{array}{l}\text { Student performance prediction model based on supervised machine learning } \\
\text { algorithms (decision tree, Naïve Bayes, logistic regression, support vector machine, } \\
\text { K-nearest neighbor, and minimal and neural sequential optimization Network). }\end{array}$ \\
\hline 32 & Maâloul and Bahou [55] & SCOPUS & $\begin{array}{l}\text { Recommendation system based on machine learning that is fundamentally based on a } \\
\text { digital learning technique (i.e., semisupervised learning) and that determines the } \\
\text { degree of similarity between students. }\end{array}$ \\
\hline 33 & Freitas et al. [56] & SCOPUS & $\begin{array}{l}\text { IoT system for predicting school dropout using machine learning techniques based on } \\
\text { socioeconomic data. }\end{array}$ \\
\hline 34 & Villegas-Ch et al. [57] & SCOPUS & $\begin{array}{c}\text { Integration of technologies, with artificial intelligence }(\mathrm{AI}) \text { and data analysis, with } \\
\text { learning management systems to improve learning. }\end{array}$ \\
\hline
\end{tabular}


Table 3. Cont.

\begin{tabular}{|c|c|c|c|}
\hline ID & Authors & Source & Summary \\
\hline 35 & Villegas-Ch et al. [58] & SCOPUS & $\begin{array}{l}\text { Architecture for Integration of Chatbot with Artificial Intelligence in Intelligent } \\
\text { Campus for Improvement of Learning. }\end{array}$ \\
\hline 36 & Han and $\mathrm{Xu}[59]$ & ScienceDirect & Intelligent education platform based on deep learning and image detection. \\
\hline 37 & Shi et al. [60] & ScienceDirect & $\begin{array}{l}\text { Learning path recommendation model based on a multidimensional knowledge } \\
\text { graph structure. }\end{array}$ \\
\hline 38 & Chang et al. [61] & IEEE & $\begin{array}{l}\text { Ontology capable of mapping students interaction data with respect to a set of tutorial } \\
\text { actions, allowing an artificial tutor to observe students and their interactions with the } \\
\text { learning environment and provide an appropriate tutoring. }\end{array}$ \\
\hline 39 & Rajkumar and Ganapathy [62] & IEEE & Recommendation system to increase classification accuracy. \\
\hline 40 & Ruangvanich et al. [63] & IEEE & $\begin{array}{l}\text { Architecture of a learning analysis system in a virtual intelligent learning environment } \\
\text { as a tool to support student learning. }\end{array}$ \\
\hline 41 & Barlybayev et al. [64] & IEEE & Intelligent system for assessing students' professional skills levels in e-learning. \\
\hline 42 & Leithardt et al. [65] & IEEE & Control system for learning environments specialized in special education. \\
\hline 43 & Lin et al. [66] & Springer & $\begin{array}{l}\text { Complementary recommendation structure for freshmen under restrictions or } \\
\text { requirements, based on objective-oriented standards. }\end{array}$ \\
\hline 44 & Chen et al. [67] & Springer & Phased forecasting model to predict students at risk at different stages of a semester. \\
\hline 45 & Niknam and Thulasiraman [68] & Springer & Intelligent learning path recommendation based on meaningful learning theory. \\
\hline 46 & Turabieh et al. [69] & Springer & $\begin{array}{l}\text { Harris Hawks algorithm optimization enhanced as a feature selection for predicting } \\
\text { student performance. }\end{array}$ \\
\hline 47 & Iatrellis et al. [70] & Springer & Two-stage machine learning approach to predict student outcomes. \\
\hline 48 & Ullah et al. [71] & Springer & $\begin{array}{l}\text { IoT model based on Software Defined Network for student interaction, which } \\
\text { interconnects students and teacher in a smart city environment }\end{array}$ \\
\hline 49 & Nuguri et al. [72] & Springer & $\begin{array}{l}\text { Cloud-based virtual reality learning environment (VRLE) system that can be deployed } \\
\text { on high-speed networks using the platform. }\end{array}$ \\
\hline 50 & Azzi et al. [73] & Springer & Classifier capable of identifying the student's learning style in the e-learning system. \\
\hline 51 & Mendes et al. [74] & Springer & $\begin{array}{l}\text { Educational tool based on motion detection using the Kinect sensor in a game that is } \\
\text { projected on the classroom wall. }\end{array}$ \\
\hline
\end{tabular}

Lagman and Mansul [44] conducted a study with individualized and personalized learning, adapted to specific learning requirements and preferences. The research focuses on student assessments and learning as the main key component of e-learning processes. The system captures student's e-learning paths, determines difficult topics and subjects, and provides intervention to the learning process. The system helps students to improve their performance.

Chanaa and Faddouli [30] created a model with three main components: cognitive analysis, learning style, and sentimental analysis. The model uses trails of learners when using a learning management system to find convenient information about students. In addition, the model also improves course completion rate and provides appropriate content to meet individual student needs.

Kolekar et al. [43] focused on the characteristics of students and the development of user interfaces according to their learning styles. The sample selected was the second-year engineering students, comprising seventy-six students grouped into two class units called experimental and control groups. The inference proves that the identification of learning styles and recommendation of course content and topics increase students' performance.

Khosravi et al. [51] developed an adaptable, scalable, content-independent learning system (RiPPLE) that depends on crowdsourcing and partnering with students to develop learning resources that are served by adaptive forms. RiPPLE is an adaptive learning system that recommends personalized learning activities to students, based on their state of knowledge. The system recommends from a grouping of crowdsourced learning activities that are generated and evaluated by educators and students themselves. 
Villegas-Ch et al. [57] proposed the integration of technologies, such as artificial intelligence (AI) and data analysis, with learning management systems to improve learning. The proposal was based on an online education model from a university in Ecuador. As a tool, the model used an LMS, where students had sections with resources and activities that served for the training of the model.

Villegas-Ch et al. [57] presented an assistant for students and teachers, allowing for the management of students' calendars, as well as the generation of events and reminders. The assistant sends notifications to students informing them which activities must be performed. In addition, it performs continuous monitoring, allowing students to improve their performance.

Han and $\mathrm{Xu}$ [59] proposed an intelligent education system that was customized to provide students with resources to suit their perceptions when starting the platform. The systems provide an environment with a full range of asynchronous and synchronous communication tools. The designed system requires a combination of sensors, devices, software, applications, and services in real-time.

Chang et al. [61] developed an ontology capable of mapping student interaction data to a set of tutoring actions. This mechanism allowed an artificial tutor to observe students in terms of their interactions with the learning environment. It also provides an appropriate tutoring action to improve the learning process. The learning environment discretizes the learning process in a sequence of activities, and the student's interaction data comes from the last activity but also includes a set of data aggregating information from previous activities (learning history). Although normally an ontology is built by humans (knowledge engineers and experts in the field), in this work, the authors proposed an automatic process of building ontology.

Ruangvanich et al. [63] developed a learning analysis system as a tool to support student learning. The technologies have been proposed as a means of supporting reflective practice based on instructor data, and these technologies are considered a priority in educational research and innovation. The system consists of ten elements, namely: Virtual Learning Environment, Learning Analysis, Alert, LMS, Learning Records, Stakeholders, Data, Student Information, Learn Direct, and Report Information.

Azzi et al. [73] proposed a classifier capable of identifying the student's learning style in the E-Learning System. The student's learning behavior was captured in different contexts, usually in different courses related to a specific subject. Web usage mining was used to capture students' behaviors, and then learning styles were mapped to the FelderSilverman Learning Style Model (FSLSM) categories. The authors used the Fuzzy C Means (FCM) algorithm to group the behavioral learning data.

Ullah et al. [71] proposed the IoT model based on Software Defined Network (RDS) for student interaction, which interconnects students to a teacher in a smart city environment. Students and teachers are free to move anywhere, anytime, and with any hardware. An RDS-IMSI model interconnects students with the teacher through their heterogeneous IoT devices.

Nuguri et al. [72] presented vSocial, a cloud-based virtual reality learning environment (VRLE) system that can be deployed on high-speed networks using the high-fidelity "social VR" platform. For the development of vSocial, the authors relied on the use of an existing special education VLE, the iSocial that trains young people with Autism Spectrum Disorder through the implementation of the Social Competence Intervention (SCI) curriculum.

Leithardt et al. [65] developed a control system for learning environments specialized in special education. Among its many possible uses, the system focuses on managing the attendance to classes of special education students, teachers, and other classroom users through the use of widespread and ubiquitous technologies. The system aims to contribute to the extension of pervasive computing systems to educational environments.

Mendes et al. [74] proposed an educational tool based on motion detection using the Kinect sensor in a game that is projected on the classroom wall. Students use balls to hit the projected elements. These collisions are detected by the sensor and registered in the 
program, thus completing the task in question. According to the authors, the system and architecture were designed to make life easier for teachers in promoting physical activity in combination with classroom learning. The proposed system is based on the projection of educational activities and the possibility for students or users to interact with them through the exercises.

Table 4 presents the 17 works with learning systems from 51 articles analyzed. In addition, Figure 1 presents the learning systems and technologies used by the researchers in the articles. Among the main technologies, Deep Learning Algorithms stood out with three articles.

Table 4. Articles containing learning systems.

\begin{tabular}{|c|c|}
\hline Authors & Learning Systems \\
\hline Chanaa and Faddouli [30] & Custom model with 3 main components, cognitive analysis, learning style, and sentiment analysis. \\
\hline Dahdouh et al. [25] & Online learning systems based on big data technologies and cloud computing. \\
\hline Kolekar et al. [43] & User interface personalized through learning styles. \\
\hline $\begin{array}{l}\text { Kozierkiewicz-Hetmańska and } \\
\text { Zyundefinedk [27] }\end{array}$ & Algorithm to determine an opening learning scenario based on the ant colony optimization technique. \\
\hline Lagman and Mansul [44] & $\begin{array}{l}\text { System dedicated to monitor the pathways in e-learning environments. The system can detect difficult subjects } \\
\text { and provide intervention in learning process. }\end{array}$ \\
\hline Lavoie and Proulx [24] & Learning management system with unique features oriented to inverted courses. \\
\hline Wang et al. [26] & Intelligent teaching assistant system that replaces the way the user waits for manual response. \\
\hline Khosravi et al. [51] & $\begin{array}{l}\text { Adaptive learning system with a focus on the student, scalable and independent of content that depends on } \\
\text { crowdsourcing and partnership with students for the development of learning resources. }\end{array}$ \\
\hline Villegas-Ch et al. [57] & Integration of technologies, with AI and data analysis, with learning management systems to improve learning. \\
\hline Han and $\mathrm{Xu}[59]$ & Intelligent education platform based on deep learning and image detection. \\
\hline Chang et al. [61] & $\begin{array}{l}\text { Ontology to mapping student interaction data with respect to a set of tutorial actions, allowing an artificial tutor } \\
\text { to observe the student and his interactions with the learning environment. }\end{array}$ \\
\hline Ruangvanich et al. [63] & $\begin{array}{c}\text { Architecture of a learning analysis system in a virtual intelligent learning environment as a tool to support } \\
\text { student learning. }\end{array}$ \\
\hline Leithardt et al. [65] & Control system for learning environments specialized in special education. \\
\hline Ullah et al. [71] & $\begin{array}{l}\text { IoT model based on Software Defined Network for student interaction, which interconnects students to a teacher } \\
\text { in a smart city environment. }\end{array}$ \\
\hline Nuguri et al. [72] & $\begin{array}{l}\text { Cloud-based virtual reality learning environment (VRLE) system that can be deployed on high-speed networks } \\
\text { using the platform. }\end{array}$ \\
\hline Azzi et al. [73] & Classifier capable of identifying the student's learning style in the e-learning system. \\
\hline Mendes et al. [74] & $\begin{array}{c}\text { Educational tool based on motion detection using the Kinect sensor in a game that is projected on the } \\
\text { classroom wall. }\end{array}$ \\
\hline
\end{tabular}

\subsection{Recommendation Systems}

Huang et al. [38] proposed a new deep reinforcement learning framework for Exercise Recommendation (DRE). Two exercise $Q$ networks (EQN) were proposed to select exercise recommendations following different mechanisms, namely, a direct EQNM with Markov property and a sophisticated EQNR with a recurrent way. Three domain-specific rewards were also leveraged to characterize the benefits of factors such as review and exploration, smoothness, and engagement to enable the DRE to find the optimal recommendation strategy. The work carried out experiments on two sets of real-world data. The results show that the proposed DRE can effectively learn from student interaction data to optimize multiple objectives in a single unified structure and adaptively recommend appropriate exercises to students.

Joy et al. [40] proposed an ontology to integrate the student's profile and the attributes of the learning objects. The ontology conceptualizes the characteristics of the student and the learning object and suggests an adaptive learning environment. The static and dynamic characteristics of a student are considered in the ontology. The static data are collected 
directly through forms and questionnaires, and the dynamic data are collected by tracking student behavior while interacting through a learning management system.

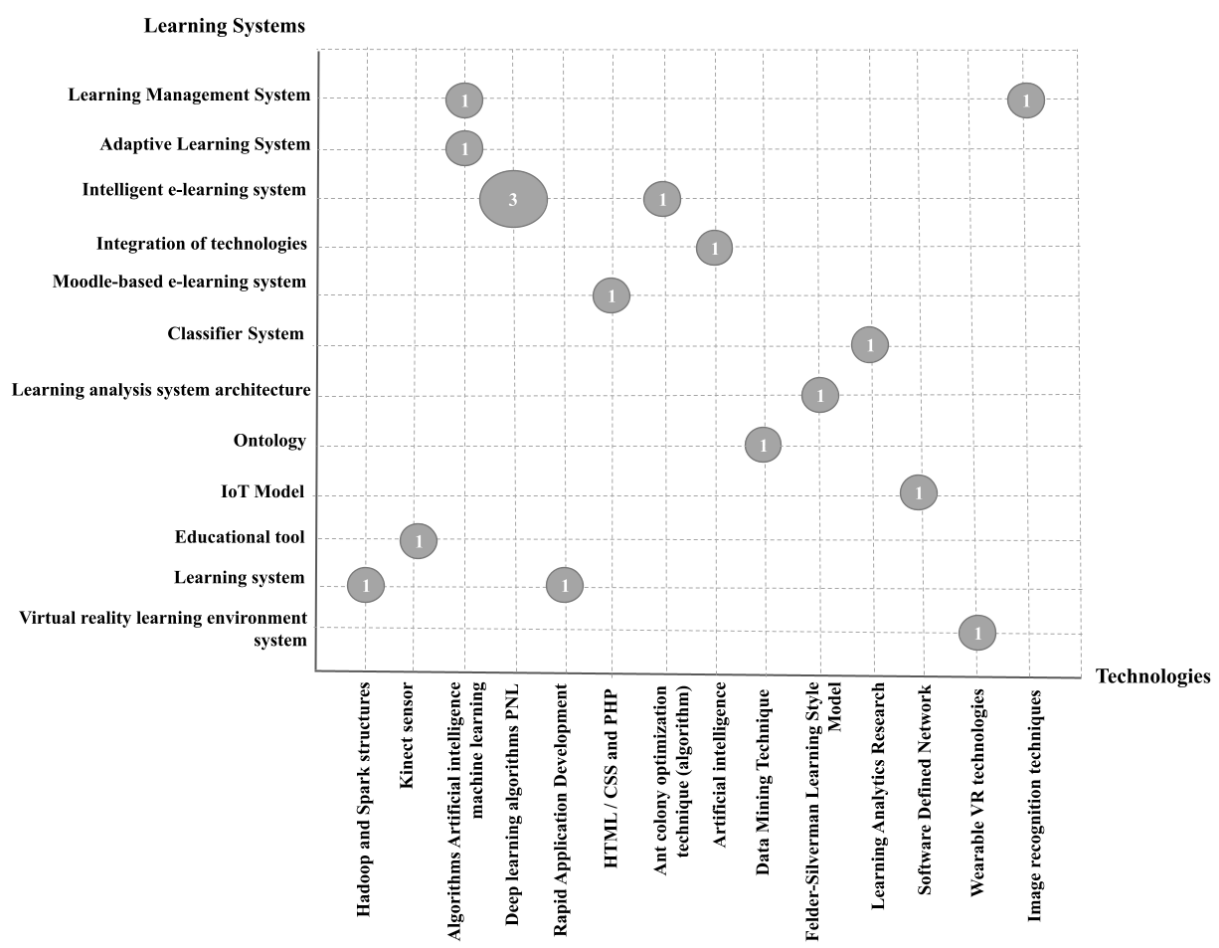

Figure 1. Learning system and technology.

Kapembe and Quenum [41] presented a hybrid recommendation model, based on the student's profile, in which the value and quality of learning objects for the program in which the student is enrolled and the student comments. The approach uses student learning behavior, performance, and interests to suggest learning objects based on the student's profile. The recommendation system consists of two components, the contentbased learning object filtering module, and the collaborative filtering module.

Sharma and Ahuja [46] presented an integrated approach to semantic recommendation using ontology to recommend relevant and personalized learning content to students. According to the authors, during their early stages, recommendation systems often face the problem of cold booting. This is due to the scarcity of information available during these phases. The proposed system approaches this problem, maintaining an ontological approach to the user profile and improving the accuracy of the recommendations during the experiment.

Florian et al. [36] presented a study based on Engeström's Activity Theory and the Actuator-Indicator model as pillars to implement an apprentice model based on Moodle's activities. The authors developed a prototype that implements indicators as examples of analytical learning applications. The prototyping process indicated that Moodle activity tracking includes data on more complex social structures. The authors analyzed the reuse of Moodle tracking data for modeling students and groups. Moodle's activity log was used to build advanced models based on students' activities in social contexts and their implications for learning support.

Anaya et al. [28] proposed a recommendation system based on Influence Diagrams (ID) for collaborative learning in the e-learning environment. The ID solution provided a recommendation decision table, which alerts to problematic situations. An ID was proposed including the essential variables to assess the student's collaboration and the variable that represents whether there was a collaboration or not.

Hamada [37] developed an improved version of a learning style index, considering students' cultural differences. The model allows students to verify their learning prefer- 
ences, and teachers have a broader view of their students' learning preferences. The model was integrated into an e-learning system based on Java2D technology that contains a set of learning materials to support students.

Chen et al. [31] created an enhanced recommendation method called Adaptive Recommendation based on Online Learning Style (AROLS). This method is integrated into a comprehensive learning style model for online learners. The method makes recommendations considering the learning style as previous knowledge. First, it generates groups of students of different learning styles. Second, the behavioral patterns represented by the similarity matrix of learning resources and the membership rules of each cluster are extracted using the students' browsing history, creating a set of custom recommendations of variable size according to the data mining results of the previous steps.

Iqbal et al. [39] proposed a context-aware framework for both user- and item-based versions by using the kernel mapping concept in collaborative filtering. The Kernel mapping recommender system algorithm is based on a novel structure learning technique. This framework has the flexibility to exploit various user- and item-related contexts during the recommendation process using different kernels that influence the performance of the system by improving the predictive accuracy, scalability, and flexibility factors. The proposed algorithm was compared with pre- and post-filtering approaches since they are the favorite approaches in the literature to solve the problem of context-aware recommendation.

A system for course recommendation distributed to the e-learning platform was also developed by Dahdouh et al. [32]. The system aims to discover the relationships between the student's activities using the association rules method to help choose the most appropriate learning materials. In addition, it was used to analyze historical data passed from enrollment in courses or registration data. The article especially discussed the concept of frequent itemsets for determining interesting rules in the database. The extracted rules are then used to find the most appropriate course according to the student's profile. The recommendation system uses big data technologies and techniques.

Venugopalan et al. [48] proposed a content-based recommendation system based on pedagogical content modeling. The system considers user queries and finds the best match. The experiment validated the system involving students seeking engineering education. The results showed that the system presents a high recovery of relevant and accurate results.

Zakrzewska [49] presented an agent-based recommendation system, which, for each new student, suggests a group of students with a similar profile and indicates corresponding learning resources. The method can be used when creating the course or when creating activities for groups. The system assumes that groups of students were created based on similar characteristics, such as usability preferences, similar behaviors, or cognitive styles. The tests were done with real data and different groups of students. The performance of the technique was validated based on student data described by cognitive traits, such as the dimensions of the dominant learning style.

The work proposed by Rajkumar and Ganapathy [62] found a correlation between introverted and extroverted personality types and their corresponding learning styles. The modified VARK questionnaire was implemented as a chatbot to classify individuals. After chatbot evaluations, all students (introverts and extroverts) watched the visual and auditory content in a completely silent environment. While watching the content, the students' Beta brainwaves were recorded, and a dataset was created at an interval of one second. This dataset was validated using machine learning classification algorithms such as Naïve Bayes, N48 tree, and clustering algorithms, improving the accuracy of students' classification.

Maâloul and Bahou [55] proposed a recommendation system that is fundamentally based on a digital learning technique (that is, semisupervised learning) and that determines the degree of similarity between the students, to recommend the items corresponding to the interest of the student. The system aims to process student profiles from the elearning platform. The proposal aims to predict and determine student preferences based on information shared on their different social media. 
Shi et al. [60] proposed a learning path recommendation model based on a multidimensional knowledge graph structure. Initially, the authors designed a multidimensional knowledge graph structure that separately stores learning objects organized in several classes. Then, they proposed six main semantic relationships between learning objects in the knowledge graph. Second, they designed a path recommendation model based on the multidimensional knowledge graph structure. The model generates and suggests personalized learning paths according to the student's target learning object. The results of the experience indicated that the proposed model can generate and recommend qualified and personalized learning paths to improve learning experiences.

Lin et al. [66] proposed a complementary recommendation framework for freshmen under constraints or requirements, based on goal-oriented standards. Students can obtain the results of recommendations according to different types of learning objectives. The structure developed by the authors presents the following contributions: (1) convex optimization framework through the integration of the characteristics of the university's courses and students and (2) data-based machine learning algorithm using resources extracted from formatted and unformatted data.

Niknam and Thulasiraman [68] designed and implemented a learning path recommendation (LPR) system. The system groups students and chooses a suitable learning path for students based on their prior knowledge. The clustering component used the Fuzzy C-Mean (FCM) algorithm, which can recommend more than one learning path for students located on the cluster boundaries. The effectiveness of the LPR system was assessed by developing and offering a database course for real students.

Villegas-Ch et al. [58] proposed an architecture for the integration of a chatbot with artificial intelligence in an intelligent campus for improving learning. The authors developed a model that integrates the identification and evaluation of variables through the analysis of data that students generate in the academic systems. The results of the data analysis are transferred to an AI tool for decision making.

Among the 51 articles evaluated, Table 5 presents 18 works with different recommendation systems to use as strategies to improve students' learning.

Figure 2 shows the distribution of recommendation systems and technologies used by researchers in the articles. Among the main technologies, the most used were machine learning techniques with three articles.

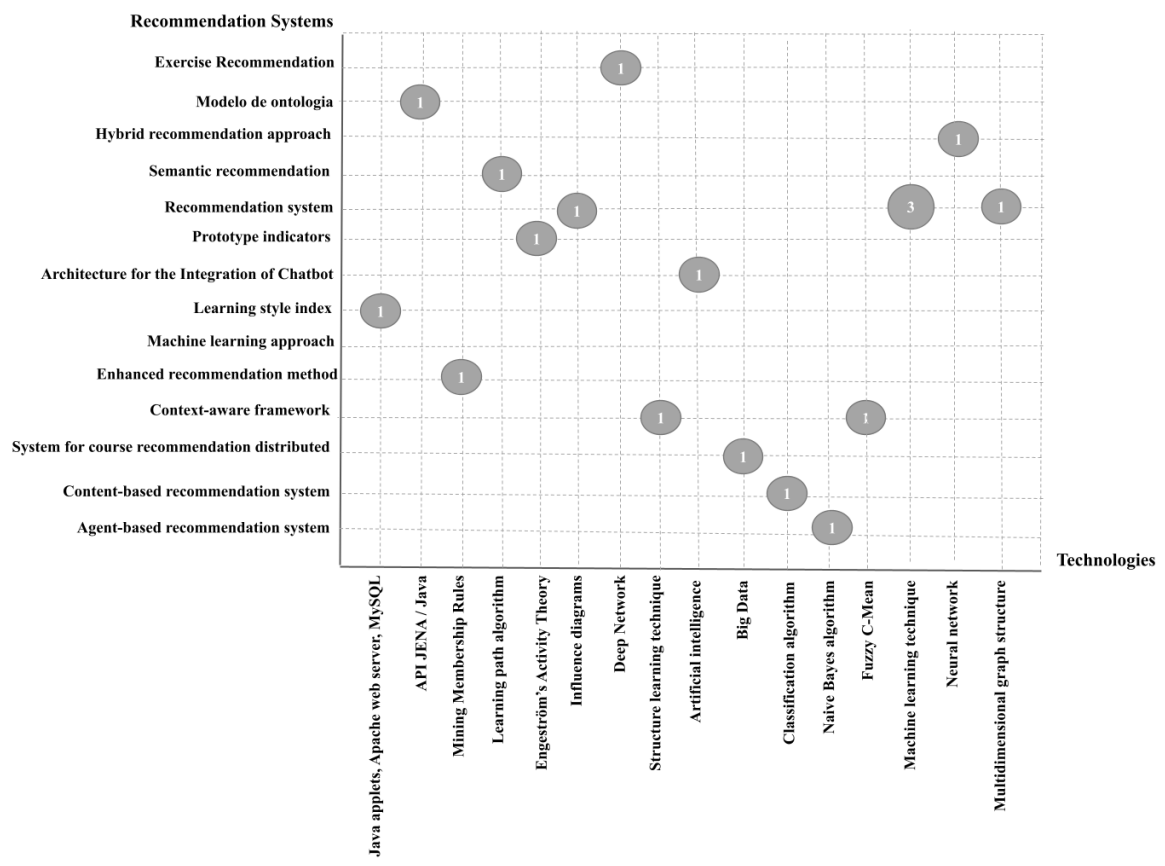

Figure 2. Recommendation systems and technologies used. 
Table 5. Articles that contain recommendation systems.

\begin{tabular}{|c|c|}
\hline Authors & Recommendation Systems \\
\hline Anaya et al. [28] & Recommendation system based on an ID in the context of collaborative learning in the e-learning environment. \\
\hline Joy et al. [40] & $\begin{array}{l}\text { Ontology model that encompasses the student profile and learning object attributes, which can be used for } \\
\text { recommending content on an e-learning platform. }\end{array}$ \\
\hline Chen et al. [31] & $\begin{array}{l}\text { Enhanced recommendation method called Adaptive Recommendation based on Online Learning } \\
\text { Style (AROLS). }\end{array}$ \\
\hline Dahdouh et al. [32] & System of recommendation of courses distributed to the e-learning platform. \\
\hline Florian et al. [36] & System supporting indicators related to applications of learning analytics. \\
\hline Hamada [37] & $\begin{array}{l}\text { Model of an e-learning system based on Java2D technology and containing an intensive set of learning } \\
\text { materials to support all types of students. }\end{array}$ \\
\hline Huang et al. [38] & Deep Reinforcement learning structure for Exercise Recommendation. \\
\hline Iqbal et al. [39] & Kernel Context Recommendation System algorithm, which is flexible, fast, and accurate. \\
\hline Kapembe and Quenum [41] & $\begin{array}{l}\text { Hybrid recommendation, based on the student's profile, the relevance and quality of learning objects for the } \\
\text { program in which the student is enrolled. }\end{array}$ \\
\hline Sharma and Ahuja [46] & $\begin{array}{l}\text { Semantic recommendation using ontology to recommend relevant and personalized learning content } \\
\text { to students. }\end{array}$ \\
\hline Venugopalan et al. [48] & Content-based recommendation system. \\
\hline Zakrzewska [49] & $\begin{array}{c}\text { Agent-based recommendation system, which, for each new student, suggests a group of students of } \\
\text { similar profiles. }\end{array}$ \\
\hline Maâloul and Bahou [55] & $\begin{array}{l}\text { Recommendation system based on machine learning that is fundamentally based on a digital learning } \\
\text { technique and that determines the degree of similarity between students. }\end{array}$ \\
\hline Villegas-Ch et al. [58] & $\begin{array}{c}\text { Architecture for Integration of Chatbot with Artificial Intelligence in Intelligent Campus for Improvement } \\
\text { of Learning. }\end{array}$ \\
\hline Shi et al. [60] & Learning path recommendation model based on a multidimensional knowledge graph structure. \\
\hline Rajkumar and Ganapathy [62] & Recommendation system to increase classification accuracy. \\
\hline Lin et al. [66] & $\begin{array}{c}\text { Complementary recommendation structure for freshmen under restrictions or requirements, based on } \\
\text { objective-oriented standards. }\end{array}$ \\
\hline Niknam and Thulasiraman [68] & Intelligent learning path recommendation based on meaningful learning theory. \\
\hline
\end{tabular}

\subsection{Forecasting Models or Systems}

Table 6 presents prediction models or systems observed in 13 articles among the 51 analyzed.

El Fouki et al. [34] proposed a decision-making system that helps instructors respond to problems using intelligent general techniques applied to data collected on e-learning platforms. The adapted system explores parameters such as learning styles and teaching styles, based on deep neural network algorithms and reinforcement learning, and takes into account the use of the teacher to improve the accuracy of the recommendation system. Principal component analysis and reinforcement learning improve classification models and increase the prediction performance of a deep neural network algorithm, reducing the dimensionality of dataset variables, with accuracy and reliability.

Manhães et al. [45] proposed the WAVE architecture that supports useful information on the performance of undergraduate students and predicts those who are at risk of dropping out of the educational system. The authors used several classifier algorithms. The Naïve Bayes algorithm showed the highest true positive rate in the three undergraduate courses analyzed.

El Moustamid et al. [35] developed a multimedia recommendation system capable of analyzing student profiles and indexing videos on the web to offer a database with courses according to the student's level, aiming at their improvement. The first block represents a standard learning management system. In this block, the students must authenticate themselves. The second block represents a system that retrieves the results, processes, and converts them into exploitable data, and then sends to the third block in the form of an order. The third block retrieves the data from the second block and looks for videos that 
are located on the web or in a data source provided by the user and keeps the videos that match the student's profile.

Table 6. Articles that contain forecast models or systems.

\begin{tabular}{|c|c|}
\hline Authors & Forecast Models or Systems \\
\hline El Fouki et al. [34] & System for assisting instructors to take decisions. \\
\hline El Moustamid et al. [35] & $\begin{array}{l}\text { System that analyzes students profiles and indexes videos on the web in order to offer students a database with } \\
\text { courses that correspond to their levels. }\end{array}$ \\
\hline Kim and Kim [42] & $\begin{array}{l}\text { Individualized Tutor of Artificial Intelligence as a system that integrates three developmental learning networks } \\
\text { (DLNS). }\end{array}$ \\
\hline Manhães et al. [45] & WAVE architecture that provides useful information about student performance. \\
\hline Thai-Nghe et al. [47] & Techniques of recommendation for mining educational data, especially to predict student performance. \\
\hline Zaoudi and Belhadaoui [50] & $\begin{array}{l}\text { Learner Behavior Analytics (LBA) model that uses a system called Score and Behavior Analytics (SBAN) to analyze } \\
\text { student outcomes and behavior. }\end{array}$ \\
\hline Chen et al. [67] & Phased forecasting model to predict students at risk at different stages of a semester. \\
\hline Turabieh et al. [69] & Harris Hawks algorithm optimization enhanced as a feature selection for predicting student performance. \\
\hline Iatrellis et al. [70] & Two-stage machine learning approach to predict student outcomes. \\
\hline Angeline et al. [53] & Discriminant analysis to measure student performance. \\
\hline Zhang et al. [52] & $\begin{array}{l}\text { Learning analysis using Moodle plugins to discover possibilities to improve the learning process and reduce the } \\
\text { number of underperforming students using plugins from the virtual Moodle environment. }\end{array}$ \\
\hline Hashim et al. [54] & $\begin{array}{c}\text { Student performance prediction model based on supervised machine learning algorithms (decision tree, Naïve } \\
\text { Bayes, logistic regression, support vector machine, K-nearest neighbor, and minimal and neural sequential } \\
\text { optimization Network). }\end{array}$ \\
\hline Freitas et al. [56] & IoT system for predicting school dropout using machine learning techniques based on socioeconomic data. \\
\hline
\end{tabular}

Thai-Nghe et al. [47] proposed a new approach that uses recommendation system techniques for educational data mining to predict student behavior. Recommendation systems techniques were compared with traditional regression methods, using data from intelligent tutoring systems. The work presented the following contributions: (1) the application of recommendation systems techniques, such as matrix factoring in the educational context, to predict student performance; (2) educational data mapping research; and (3) comparison of recommendation systems with traditional techniques such as linear regression or logistic regression. Experimental results showed that the proposed approach can improve prediction results.

Kim and Kim [42] developed an individualized AI tutor as a system that integrates three Developmental Learning Networks (DLNs) to help a student achieve a high level of academic success. The AI Tutor suggests learning content that matches the educational standard of the academic grade. The AI tutor considers the student's current status and preferences to deliver education programs on an individual basis.

Zaoudi and Belhadaoui [50] proposed a Learner Behavior Analytics (LBA) model based on a system called Score and Behavior Analytics (SBAN) to analyze student outcomes and behavior. This model would be responsible for continuously monitoring and evaluating the student's actual level throughout their training trajectory. The authors intended to further detail these models, proposing an architecture and prototypes that would allow better modeling for the LBA system, making it possible to present content more adaptable to the profiles of evolving students.

Chen et al. [67] proposed a phased forecasting model to predict at-risk students in different semesters. Students' characteristics and online learning behaviors were analyzed.The proposed model has three main contributions: (1) restriction strategies to obtain valuable resources; (2) a dynamic prediction model; and (3) it can predict at-risk students at different stages of the semester.

Iatrellis et al. [70] proposed a two-stage machine learning approach that uses supervised and unsupervised learning techniques to predict outcomes for students in higher 
education. The objective of the research was to predict the results of students in undergraduate courses in computer science offered by higher education institutions in Greece. Students involved in the case study were grouped based on the similarity of educationrelated factors and metrics. The K-means algorithm was used in the clustering experiments, and the result produced evidence that the proposed approach can contribute to the accuracy of predicting student outcomes.

Turabieh et al. [69] simulated the proposed modification of the Harris Hawks Optimization algorithm as a resource selection algorithm for the students' performance prediction problem. The proposed approach improves the original Harris Hawks Optimization algorithm and supports the claim that the control of population diversity improves the process of exploring the algorithm.

Zhang et al. [52] performed learning analytics to discover possibilities to improve the learning process and reduce the number of underperforming students using plug-ins from the Moodle virtual environment. The analysis considered records of 124 participants, to verify the relationship between the amount of records in the e-course and the students final grades. The authors also performed a correlation analysis to determine the impact of students' educational activity on the Moodle system in the final assessment.

Angeline et al. [53] used discriminant analysis to measure student performance. The data-mining technique identified students' cognitive skills and their associated behaviors in a virtual instructor-led classroom. The datasets collected in the research study refer to different subjects addressed by students of engineering graduates from Dr. G. U. Pope College of Engineering (Hyderabad, India). The students' performances in the respective discipline prerequisites were collected from the departmental records of summaries of results related to the computer science course and the engineering discipline. According to the authors, the discriminant analysis works well with the dataset covering all data groups and provides a better forecast.

Hashim et al. [54] compared the performance of various supervised machine learning algorithms to predict students' academic success and their performance in higher education. The authors used a set of data provided by the courses in the bachelor's degree programs of the Faculty of Informatics and Information Technology at the University of Basra, in the 2017-2018 and 2018-2019 academic years, to predict student performance on final exams. The experiments showed that the Logistic Regression classifier algorithm demonstrated the best performance.

Freitas et al. [56] proposed an approach to detect and classify students at risk of dropping out based on their socioeconomic data. The IoT platform was designed to allow this task to be performed using any device connected to the Internet. Machine learning methods were used to identify the possibility of evasion.

Figure 3 shows the distribution of forecast models or systems and technologies used by researchers in the articles. The 13 works contain proposals that identify the characteristics and profiles of students with learning problems and probable dropout before the end of the course, enabling actions to improve the learning process.

\subsection{Assessment Tool}

Among the 51 articles analyzed, only three presented assessment tools (Table 7): Domain-specific language to customize online learning assessments in Moodle [29], a system called Enriched Learning Analytics Rubric (LAe-R) [33], and an intelligent system for assessing students' professional skills levels in e-learning [64].

Balderas et al. [29] developed a domain-specific language to customize online learning assessments in Moodle. The authors implemented EvalCourse, a computer system that performs queries written in this language, providing in the output the requested information. In this way, teachers can retrieve the indicators of information stored in Moodle activity logs without any technical knowledge in databases or computer programming. The study was carried out at the University of Cádiz, Spain, in a mandatory course of 
Language Processors II from its degree in Computer Science, with 36 students from the first semester and the fifth year enrolled in the academic year 2012/13.

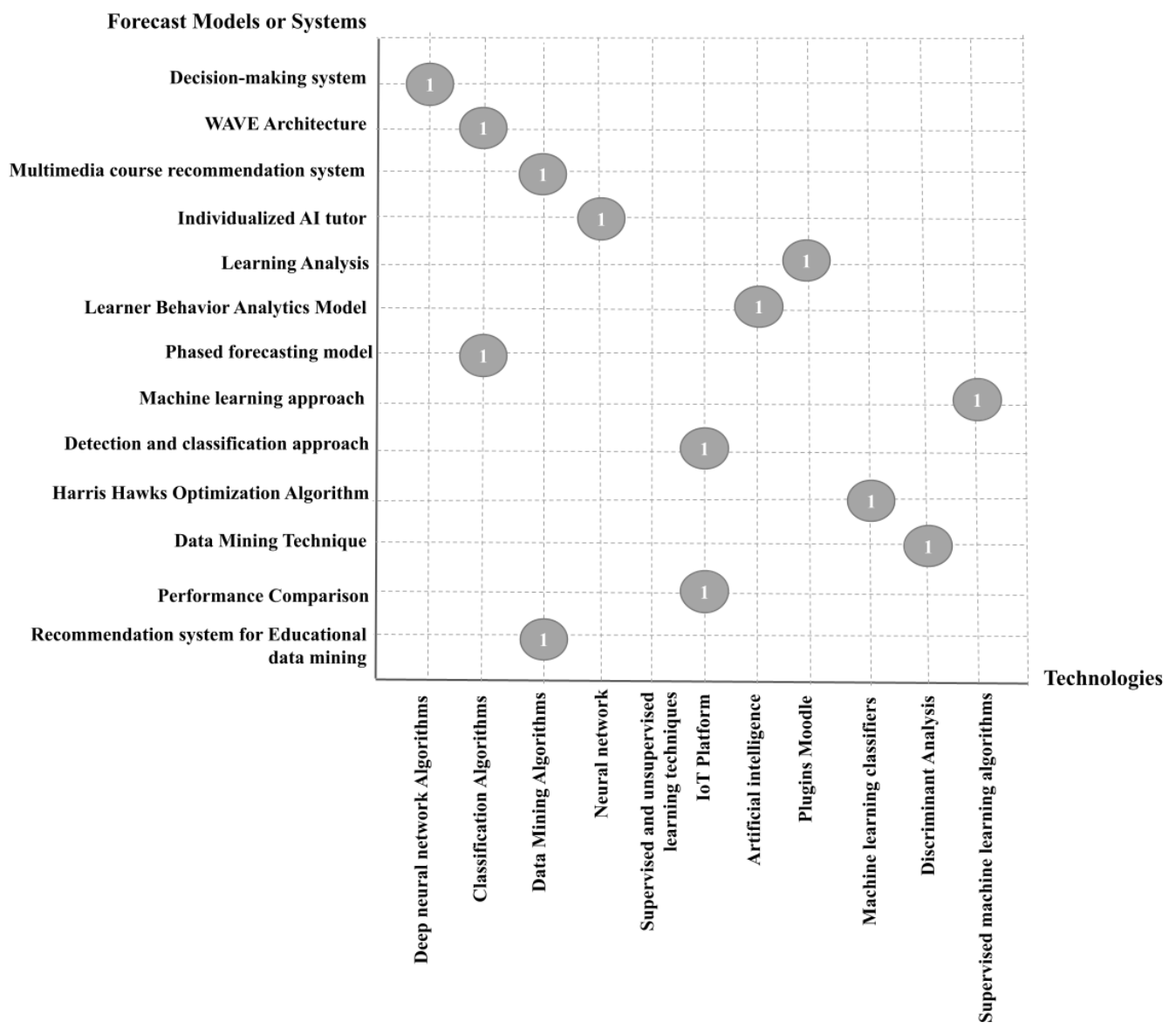

Figure 3. Prediction models or systems and technologies used.

Table 7. Articles that contain an assessment tool.

\begin{tabular}{cc}
\hline Authors & Summary/Assessment Tool \\
\hline Balderas et al. [29] & Domain-specific language to customize online learning assessments in Moodle. \\
Dimopoulos et al. [33] & A tool called Enriched Learning Analytics Rubric (LAe-R), developed as a Moodle plug-in. \\
Barlybayev et al. [64] & Intelligent system for assessing students' professional skills levels in e-learning. \\
\hline
\end{tabular}

Dimopoulos et al. [33] presented an evaluation tool called Enriched Learning Analytics Rubric (LAe-R), which was developed as a Moodle plug-in. LAe-R allows teachers to create enriched rubrics containing related criteria and classification levels. For this, data extracted from the analysis of student interaction and learning behavior in a course in the Moodle environment are used, such as the number of messages posted, access times, material, and task notes. LAe-R was considered a stable and promising assessment tool that can fill the gap in evaluating student performance in e-learning environments using student interaction data.

Barlybayev et al. [64] proposed the creation of an intelligent system for assessing students' professional skills levels in e-learning. Mathematical models and methods were used to evaluate the formation of students' professional skills at the level of subjects, modules, and the entire educational program. Competency (knowledge) assessments were carried out at the three levels of the educational program. To assess knowledge, fuzzy binary relationships were used with standard responses from the knowledge base and the responses of students. The authors used fuzzy calculations on data obtained by the 
comparison algorithm. The construction of fuzzy calculations used the Mamdani method implemented in Matlab.

\section{Discussion}

This section discusses the results obtained by reviewing the literature, analyzing the articles, and identifying gaps to encourage future research. The analysis of 51 articles identified a variety of intelligent services applied to distance learning. Intelligent services were categorized as learning systems (17), recommendation systems (18), prediction systems (13), and assessment tools (3).

Section 4.1 showed that the authors proposed different learning systems that help both managers and teachers in the teaching and learning process.

Through the services offered by the learning systems, institutions can promote a quality education directed to the profile of each student. Learning systems enable teachers to help struggling students individually or in groups, select courses that best suit the student's profile, and choose learning materials best suited to the student's learning styles and level of knowledge.

In addition, learning systems contribute to interactivity between students and teachers, promote student enthusiasm for learning through continuous feedback, provide intervention to the learning process, contribute to the evolution of student performance, improve course completion rate, and provide content appropriate to meet individual student needs.

Section 4.2 showed that the proposed recommendation systems have different types of recommendations.

Recommendation systems collect and learn from students' data as they interact through a learning management system and use their learning behaviors to recommend different intelligent services such as appropriate exercises (Huang et al. [38]), objects learning (Lin et al. [66]; Kapembe and Quenum [41]; Joy et al. [40]), personalized learning content (Sharma and Ahuja [46]), supportive teaching materials (Hamada [37]), courses according to the student profile (Dahdouh et al. [32]), and personalized learning paths to enhance learning experiences (Niknam and Thulasiraman [68]).

Other referral systems also suggest groups of students with a similar profile and indicate related learning resources. The recommendation systems mostly take advantage of student-generated data when using virtual learning environments or educational systems. Data are analyzed and used to recommend intelligent services. These systems serve as a strategy to improve student learning.

The literature review in Section 4.3 also showed different systems that used student data analysis to predict the risk of failure or dropout in distance learning courses. The works presented in this section address prediction systems.

The analyzed works propose systems that identify the characteristics and profiles of students and predict their behavior (Zaoudi and Belhadaoui [50]; Thai-Nghe et al. [47]), cognitive skills (Angeline et al. [53]), academic success (Kim and Kim [42]; Hashim et al. [54]), performance (Iatrellis et al. [70]), learning styles (El Fouki et al. [34]), and potential dropout or failure (Manhães et al. [45]; Chen et al. [67];Freitas et al. [56]).

These systems help institutions to make decisions in the short, medium, and long term. The systems also enable actions to improve the teaching and learning process and reduce the failure and dropout rate.

Section 4.4 presented assessment tools, among which only three works addressed this category.

The works addressed the following themes: a domain language was developed to customize assessments and assess the performance and skills of students in the Moodle environment (Balderas et al. [29]); a tool to assess student performance and learning behavior using student interaction data, such as the number of post messages, access times to learning material and task grades (Dimopoulos et al. [33]), and, finally, an intelligent system that assesses the competence levels and the formation of professional skills of students in an educational program (Barlybayev et al. [64]). 
The literature review focused on intelligent services applied to distance learning, and during the research, lessons were learned related to the categories of services found. Table 8 presents the twelve lessons learned in this literature review.

Table 8. Lessons learned

\begin{tabular}{|c|c|}
\hline Item & Description \\
\hline 1 & $\begin{array}{l}\text { Intelligent services categorized as learning systems and recommendation systems are trends among intelligent systems. The use of } \\
\text { intelligent systems helps teachers and managers in decision making in the face of the problems found in distance learning courses. }\end{array}$ \\
\hline 2 & $\begin{array}{c}\text { Learning systems identify learning behavior patterns, identify underachieving students, and provide personalized tools or content as } \\
\text { educational support. }\end{array}$ \\
\hline 3 & Intelligent systems promote improvements in learning and make it possible to minimize the dropout rate in distance learning courses. \\
\hline 4 & Prediction systems are used in discovering student behavior patterns, predicting academic progress and possible dropout. \\
\hline 5 & $\begin{array}{l}\text { Intelligent systems allow teachers and managers to use the information to reduce problems faced in conducting distance learning courses, } \\
\text { such as failure and dropout. }\end{array}$ \\
\hline 6 & Intelligent systems can be used as a complementary educational tool to help students improve their academic performance. \\
\hline 7 & $\begin{array}{l}\text { Intelligent systems with recommendation functions can solve problems in the teaching and learning process by offering the appropriate } \\
\text { content that meets the students' individual needs and preferences. }\end{array}$ \\
\hline 8 & Intelligent systems can offer differentiated services according to the student's profile. \\
\hline 9 & Intelligent systems can be used as advanced assessment tools. \\
\hline 10 & $\begin{array}{c}\text { Intelligent systems provide statistical and analytical services by showing the data on dashboards, thus facilitating management by } \\
\text { graphically presenting the information. }\end{array}$ \\
\hline 11 & $\begin{array}{c}\text { Intelligent systems can trigger personalized alerts for multiple devices, keeping managers and system administrators informed about alerts } \\
\text { triggered via triggers for important events; messages can be directed to the responsible smartphones to take actions in time, including } \\
\text { anticipating events. }\end{array}$ \\
\hline 12 & $\begin{array}{l}\text { Intelligent systems can be configured to receive data from various IoT devices scattered in the educational environment such as entrance, } \\
\text { classroom, presence detector, proximity detectors, biometric readers, classroom temperature, and humidity. Intelligent services can also } \\
\text { receive data from mobile devices of remote students such as login date and time, connection time, and location, among others. }\end{array}$ \\
\hline
\end{tabular}

\section{Conclusions and Future Research}

Distance Learning aims to offer a complete, dynamic, and efficient teaching and learning process mediated by technological resources. It has been growing exponentially and taking an important role in the educational environment. The use of this modality allows the generation of information according to the behavior of students in Virtual Learning Environments (VLEs).

The data extracted from the VLEs are analyzed using data analysis techniques that identify student behavior patterns. The discovery of standards helps managers and teachers in strategic planning, allows monitoring the student's academic progress, and offers solutions through intelligent services for monitoring, intervention, motivation, and improvement in the students' learning process.

A research methodology based on a literature review allowed the identification of 51 publications on intelligent services applied to distance learning. Among the intelligent services, 33\% (17 articles) presented learning systems, 35\% (18 articles) contained recommendation systems, $26 \%$ (13 articles) presented models or forecasting systems, and only $6 \%$ (3 articles) contain assessment tools.

The approach presented is broad, because the work addressed educational contexts at different levels of learning, focusing on distance learning, and, therefore, the text includes generic conclusions.

The study indicated that recommendation systems and learning systems are research trends. These systems analyze student profiles, identify patterns of behavior, detect low performance, and identify the probabilities of dropouts from courses.

Most research papers analyze the learning profile to indicate personalized content and courses or extracurricular activities that contribute to student learning. In addition, the studies allow teachers and educational managers to take preventive actions to minimize possible problems in the learning paths. 
Future work will expand this literature review through a specific focus on mobile learning [75-77] and ubiquitous learning [65,78-82]. Both technologies allow expanding the limits of distance learning environments mainly collaborating to the infrastructure of intelligent systems. In this sense, the use of temporal series of contexts to organize and analyze data is an emergent research theme. This organization of data is called Context Histories [83-85] or Trails [86,87]. Context histories allow data analysis based on profile management [88], context prediction [89], and pattern and similarity analysis [90,91]. The continuation of this review will consider research works that applied Context Histories to implement intelligent services in distance learning.

Author Contributions: Conceptualization , L.M.d.S., L.P.S.D., S.R. and J.L.V.B.; investigation, L.M.d.S., L.P.S.D., S.R. and J.L.V.B.; methodology, L.M.d.S., L.P.S.D., S.R. and J.L.V.B.; software, L.M.d.S. and L.P.S.D.; project administration, J.L.V.B.; supervision, J.L.V.B.; validation, L.M.d.S., L.P.S.D., S.R. and J.L.V.B.; writing—original draft, L.M.d.S., L.P.S.D., S.R. and J.L.V.B.; writing-review and editing, L.M.d.S., J.L.V.B., V.R.Q.L. and D.R.F.L.; financial, V.R.Q.L. and D.R.F.L. All authors have read and agreed to the published version of the manuscript.

Funding: This work was supported by national funds through the Fundação para a Ciência e a Tecnologia, I.P. (Portuguese Foundation for Science and Technology) by the project UIDB/05064/2020 (VALORIZA-Research Centre for Endogenous Resource Valorization) and it was partially supported by by Fundação para a Ciência e a Tecnologia under Project UIDB/04111/2020, and ILIND-Instituto Lusófono de Investigação e Desenvolvimento, under project COFAC/ILIND/COPELABS/3/2020.

Institutional Review Board Statement: Not applicable.

Informed Consent Statement: Not applicable.

Data Availability Statement: Not applicable.

Conflicts of Interest: The authors declare no conflict of interest.

\section{Abbreviations}

The following abbreviations are used in this manuscript:

$\begin{array}{ll}\text { AI } & \text { Artificial Intelligence } \\ \text { DL } & \text { Distance Learning } \\ \text { DLNS } & \text { Developmental Learning Networks } \\ \text { EC } & \text { Exclusion Criteria } \\ \text { FCM } & \text { Fuzzy C-Mean } \\ \text { IC } & \text { Inclusion Criteria } \\ \text { ID } & \text { Influence Diagrams } \\ \text { LA } & \text { Learning Analytics } \\ \text { LBA } & \text { Learner Behavior Analytics } \\ \text { LMS } & \text { Learning Management System } \\ \text { LPR } & \text { Learning Path Recommendation } \\ \text { NLP } & \text { Natural Language Processing } \\ \text { SBAN } & \text { Score and Behavior Analytics } \\ \text { SCI } & \text { Social Competence Intervention } \\ \text { VRLE } & \text { Virtual Reality Learning Environment } \\ \text { VLEs } & \text { Virtual Learning Environments }\end{array}$

\section{References}

1. Allen, I.E.; Seaman, J. Digital Compass Learning: Distance Education Enrollment Report 2017. 2017. Available online: https:/ / files.eric.ed.gov / fulltext/ED580868.pdf (accessed on 27 May 2021).

2. WHO. Key Messages and Actions for COVID-19 Prevention and Control in Schools March 2020. 2020. Available online: https:/ / www.who.int/emergencies/diseases/novel-coronavirus-2019/technical-guidance (accessed on 2 October 2021).

3. OECD. Education Responses to COVID-19: Embracing Digital Learning and Online Collaboration; OECD Publications: Paris, France, 2020. [CrossRef]

4. Ilyashenko, L.; Markova, S.; Mironov, A.; Vaganova, O.; Smirnova, Z. Educational environment as a development resource for the learning process. Amazon. Investig. 2019, 8, 303-312. 
5. Williamson, B.; Eynon, R.; Potter, J. Pandemic politics, pedagogies and practices: Digital technologies and distance education during the coronavirus emergency. Learn. Media Technol. 2020, 45, 107-114. [CrossRef]

6. Pedró, F.; Subosa, M.; Rivas, A.; Valverde, P. Artificial Intelligence in Education: Challenges and Opportunities for Sustainable Development. 2019. Available online: https://unesdoc.unesco.org/ark:/48223/pf0000366994 (accessed on 2 October 2021).

7. Waheed, H.; Hassan, S.U.; Aljohani, N.R.; Hardman, J.; Alelyani, S.; Nawaz, R. Predicting academic performance of students from VLE big data using deep learning models. Comput. Hum. Behav. 2020, 104, 106189. [CrossRef]

8. Becker, S.A.; Cummins, M.; Davis, A.; Freeman, A.; Hall Giesinger, C.; Ananthanarayanan, V. NMC Horizon Report: 2017 Higher Education Edition; New Media Consortium: Austin, TX, USA, 2017; pp. 1-60.

9. De Andrade, T.L.; Rigo, S.J.; Barbosa, J.L.V. Active Methodology, Educational Data Mining and Learning Analytics: A Systematic Mapping Study. Inform. Educ. 2021, 20, 171-204. [CrossRef]

10. Acatech. Smart Service Welt 2018-Wo Stehen Wir? Wohin Gehen Wir? 2018. Available online: https://www.acatech.de/ publikation/smart-service-welt-2018-wo-stehen-wir-wohin-gehen-wir/ (accessed on 2 July 2021).

11. Koldewey, C.; Meyer, M.; Stockbrügger, P.; Dumitrescu, R.; Gausemeier, J. Framework and Functionality Patterns for Smart Service Innovation. Procedia CIRP 2020, 91, 851-857. [CrossRef]

12. Allmendinger, G.; Lombreglia, R. Four strategies for the age of smart services. Harv. Bus. Rev. 2005, 83, 131-138. [PubMed]

13. Koldewey, C.; Gausemeier, J.; Chohan, N.; Frank, M.; Reinhold, J.; Dumitrescu, R. Aligning Strategy and Structure for Smart Service Businesses in Manufacturing. In Proceedings of the 2020 IEEE International Conference on Technology Management, Operations and Decisions (ICTMOD), Marrakech, Morocco, 24-27 November 2020; pp. 1-8. [CrossRef]

14. Beverungen, D.; Müller, O.; Matzner, M.; Mendling, J.; vom Brocke, J. Conceptualizing smart service systems. Electron. Mark. 2019, 29, 7-18. [CrossRef]

15. Cambruzzi, W.; Rigo, S.J.; Barbosa, J.L.V. Dropout Prediction and Reduction in Distance Education Courses with the Learning Analytics Multitrail Approach. J. Univers. Comput. Sci. 2015, 21, 23-47. [CrossRef]

16. Traxler, J. Distance Learning-Predictions and Possibilities. Educ. Sci. 2018, 8, 35. [CrossRef]

17. Clow, D. An overview of learning analytics. Teach. High. Educ. 2013, 18, 683-695. [CrossRef]

18. Gašević, D.; Kovanović, V.; Joksimović, S. Piecing the learning analytics puzzle: A consolidated model of a field of research and practice. Learn. Res. Pract. 2017, 3, 63-78. [CrossRef]

19. Cummaudo, A.; Vasa, R.; Grundy, J.; Abdelrazek, M.; Cain, A. Losing Confidence in Quality: Unspoken Evolution of Computer Vision Services. In Proceedings of the 2019 IEEE International Conference on Software Maintenance and Evolution (ICSME), Cleveland, OH, USA, 29 September-4 October 2019; pp. 333-342. [CrossRef]

20. Hosseini, H.; Xiao, B.; Poovendran, R. Google's Cloud Vision API Is Not Robust to Noise. arXiv 2017, arXiv:1704.05051.

21. Marquardt, K. Smart services-Characteristics, challenges, opportunities and business models. Proc. Int. Conf. Bus. Excell. 2017, 11, 789-801. [CrossRef]

22. Hermann, S. Was Sind Smart SERVICES? [Video File]. 2016. Available online: http://www.servlab.eu/?p=1333 (accessed on 27 May 2021).

23. Koldewey, C.; Gausemeier, J.; Dumitrescu, R.; Evers, H.H.; Frank, M.; Reinhold, J. Development Process for Smart Service Strategies: Grasping the Potentials of Digitalization for Servitization. In Digitalization: Approaches, Case Studies, and Tools for Strategy, Transformation and Implementation; Springer International Publishing: Cham, Switzerland, 2021; pp. 205-237._12. [CrossRef]

24. Lavoie, F.B.; Proulx, P. A Learning Management System for Flipped Courses. In Proceedings of the 2019 the 3rd International Conference on Digital Technology in Education, Yamanashi, Japan, 25-27 October 2019; Association for Computing Machinery: New York, NY, USA, 2019; pp. 73-76. [CrossRef]

25. Dahdouh, K.; Dakkak, A.; Oughdir, L.; Messaoudi, F. Big data for online learning systems. Educ. Inf. Technol. 2018, 23, 2783-2800. [CrossRef]

26. Wang, Y.; Sun, Y.; Chen, Y. Design and Research of Intelligent Tutor System Based on Natural Language Processing. In Proceedings of the 2019 IEEE International Conference on Computer Science and Educational Informatization (CSEI), Kunming, China, 16-19 August 2019; pp. 33-36. [CrossRef]

27. Kozierkiewicz-Hetmańska, A.; Zyundefinedk, D. A Method for Determination of an Opening Learning Scenario in Intelligent Tutoring Systems. In Proceedings of the 5th Asian Conference on Intelligent Information and Database Systems-Volume Part II, Lumpur, Malaysia, 18-20 March 2013; Springer: Berlin/Heidelberg, Germany, 2013; pp. 129-138._14. [CrossRef]

28. Anaya, A.R.; Luque, M.; García-Saiz, T. Recommender system in collaborative learning environment using an influence diagram. Expert Syst. Appl. 2013, 40, 7193-7202. [CrossRef]

29. Balderas, A.; Ruiz-Rube, I.; Palomo-Duarte, M.; Dodero, J.M. A Generative Computer Language to Customize Online Learning Assessments. In Proceedings of the First International Conference on Technological Ecosystem for Enhancing Multiculturality (TEEM '13), Salamanca, Spain, 14-15 November 2013; Association for Computing Machinery: New York, NY, USA, 2013; pp. 141-147. [CrossRef]

30. Chanaa, A.; Faddouli, N.E.E. Deep learning for a smart e-Iearning system. In Proceedings of the 20184 th International Conference on Cloud Computing Technologies and Applications (Cloudtech), Brussels, Belgium, 26-28 November 2018; pp. 1-8. [CrossRef]

31. Chen, H.; Yin, C.; Li, R.; Rong, W.; Xiong, Z.; David, B. Enhanced learning resource recommendation based on online learning style model. Tsinghua Sci. Technol. 2020, 25, 348-356. [CrossRef] 
32. Dahdouh, K.; Dakkak, A.; Oughdir, L.; Ibriz, A. Large-scale e-learning recommender system based on Spark and Hadoop. J. Big Data 2019, 6, 2. [CrossRef]

33. Dimopoulos, I.; Petropoulou, O.; Retalis, S. Assessing Students' Performance Using the Learning Analytics Enriched Rubrics. In Proceedings of the Third International Conference on Learning Analytics and Knowledge (LAK '13), Leuven, Belgium, 8-13 April 2013; Association for Computing Machinery: New York, NY, USA, 2013; pp. 195-199. [CrossRef]

34. El Fouki, M.; Aknin, N.; El Kadiri, K.E. Intelligent Adapted E-Learning System Based on Deep Reinforcement Learning. In Proceedings of the 2nd International Conference on Computing and Wireless Communication Systems (ICCWCS'17), Larache, Morocco, 14-16 November 2017; Association for Computing Machinery: New York, NY, USA, 2017; pp. 1-6; Article 85. [CrossRef]

35. El Moustamid, A.; En-Naimi, E.; El Bouhdidi, J. Integration of Data Mining Techniques in E-Learning Systems: Clustering Profil of Lerners and Recommender Course System. In Proceedings of the 2nd International Conference on Big Data, Cloud and Applications (BDCA'17), Tetouan, Morocco, 29-30 March 2017; Association for Computing Machinery: New York, NY, USA, 2017, pp. 1-4; Article 97. [CrossRef]

36. Florian, B.; Glahn, C.; Drachsler, H.; Specht, M.; Fabregat Gesa, R. Activity-Based Learner-Models for Learner Monitoring and Recommendations in Moodle. In Towards Ubiquitous Learning; Kloos, C.D., Gillet, D., Crespo García, R.M., Wild, F., Wolpers, M., Eds.; Springer: Berlin/Heidelberg, Germany, 2011; pp. 111-124._10. [CrossRef]

37. Hamada, M. Learning Style Model for e-Learning Systems. In Active Media Technology; Huang, R., Ghorbani, A.A., Pasi, G., Yamaguchi, T., Yen, N.Y., Jin, B., Eds.; Springer: Berlin/Heidelberg, Germany, 2012; pp. 186-195. [CrossRef]

38. Huang, Z.; Liu, Q.; Zhai, C.; Yin, Y.; Chen, E.; Gao, W.; Hu, G. Exploring Multi-Objective Exercise Recommendations in Online Education Systems. In Proceedings of the 28th ACM International Conference on Information and Knowledge Management (CIKM '19), Beijing, China, 3-7 November 2019; Association for Computing Machinery: New York, NY, USA, 2019; pp. 1261-1270. [CrossRef]

39. Iqbal, M.; Ghazanfar, M.A.; Sattar, A.; Maqsood, M.; Khan, S.; Mehmood, I.; Baik, S.W. Kernel Context Recommender System (KCR): A Scalable Context-Aware Recommender System Algorithm. IEEE Access 2019, 7, 24719-24737. [CrossRef]

40. Joy, J.; Raj, N.S. An Ontology Model for Content Recommendation in Personalized Learning Environment. In Proceedings of the Second International Conference on Data Science, E-Learning and Information Systems (DATA '19), Dubai, United Arab Emirates, 2-5 December 2019; Association for Computing Machinery: New York, NY, USA, 2019; pp. 1-6, Article 9. [CrossRef]

41. Kapembe, S.S.; Quenum, J.G. A Personalised Hybrid Learning Object Recommender System. In Proceedings of the 11th International Conference on Management of Digital EcoSystems (MEDES '19), Limassol, Cyprus, 12-14 November 2019; Association for Computing Machinery: New York, NY, USA, 2019; pp. 242-249. [CrossRef]

42. Kim, W.H.; Kim, J.H. Individualized AI Tutor Based on Developmental Learning Networks. IEEE Access 2020, 8, $27927-27937$. [CrossRef]

43. Kolekar, S.V.; Pai, R.M.; Pai, M.M. Adaptive User Interface for Moodle based E-learning System using Learning Styles. Procedia Comput. Sci. 2018, 135, 606-615. [CrossRef]

44. Lagman, A.C.; Mansul, D.M. Extracting Personalized Learning Path in Adaptive E-Learning Environment Using Rule Based Assessment. In Proceedings of the 2017 International Conference on Information Technology (ICIT 2017), Singapore, 27-29 December 2017; Association for Computing Machinery: New York, NY, USA, 2017; pp. 335-340. [CrossRef]

45. Manhães, L.M.B.; da Cruz, S.M.S.; Zimbrão, G. WAVE: An Architecture for Predicting Dropout in Undergraduate Courses Using EDM. In Proceedings of the 29th Annual ACM Symposium on Applied Computing (SAC '14), Gyeongju, Korea, 24-28 March 2014; Association for Computing Machinery: New York, NY, USA, 2014; pp. 243-247. [CrossRef]

46. Sharma, M.; Ahuja, L. A Novel and Integrated Semantic Recommendation System for E-Learning Using Ontology. In Proceedings of the Second International Conference on Information and Communication Technology for Competitive Strategies (ICTCS '16), Udaipur, India, 4-5 March 2016; Association for Computing Machinery: New York, NY, USA, 2019; pp. 1-5; Article 52. [CrossRef]

47. Thai-Nghe, N.; Drumond, L.; Krohn-Grimberghe, A.; Schmidt-Thieme, L. Recommender system for predicting student performance. Procedia Comput. Sci. 2010, 1, 2811-2819. [CrossRef]

48. Venugopalan, S.; Srinath, M.V.; Rodrigues, P. Recommender System for E-Learning through Content and Profile Based Approach. In Proceedings of the Second International Conference on Information and Communication Technology for Competitive Strategies (ICTCS '16), Udaipur, India, 4-5 March 2016; Association for Computing Machinery: New York, NY, USA, 2016; pp. 1-5; Article 45. [CrossRef]

49. Zakrzewska, D. Building Group Recommendations in E-Learning Systems. In Agent and Multi-Agent Systems: Technologies and Applications; Jedrzejowicz, P., Nguyen, N.T., Howlet, R.J., Jain, L.C., Eds.; Springer: Berlin/Heidelberg, Germany, 2010; pp. 391-400. [CrossRef] 
50. Zaoudi, M.; Belhadaoui, H. Adaptive E-Learning: Adaptation of Content According to the Continuous Evolution of the Learner during His Training. In Proceedings of the 3rd International Conference on Networking, Information Systems \& Security (NISS2020), Marrakech, Morocco, 31 March-2 April 2020; Association for Computing Machinery: New York, NY, USA, 2020; pp. 1-6; Article 71. [CrossRef]

51. Khosravi, H.; Sadiq, S.; Gasevic, D. Development and Adoption of an Adaptive Learning System: Reflections and Lessons Learned. In Proceedings of the 51st ACM Technical Symposium on Computer Science Education (SIGCSE '20), Portland, OR, USA, 11-14 March 2020; Association for Computing Machinery: New York, NY, USA, 2020; pp. 58-64. [CrossRef]

52. Zhang, Y.; Ghandour, A.; Shestak, V. Using Learning Analytics to Predict Students Performance in Moodle LMS. Int. J. Emerg. Technol. Learn. (iJET) 2020, 15, 102-115. [CrossRef]

53. Angeline, D.M.D.; Ramasubramanian, P.; James, I.S.P. The Discriminant Analysis Approach for Evaluating Effectiveness of Learning in an Instructor-Led Virtual Classroom. Int. J. Smart Sens. Intell. Syst. 2020, 13, 1-15. [CrossRef]

54. Hashim, A.S.; Awadh, W.A.; Hamoud, A.K. Student Performance Prediction Model based on Supervised Machine Learning Algorithms. IOP Conf. Ser. Mater. Sci. Eng. 2020, 928, 032019. [CrossRef]

55. Maâloul, M.H.; Bahou, Y. Learning Management System based on Machine Learning: The Case Study of Ha'il University-KSA. Int. J. Adv. Comput. Sci. Appl. 2021, 12. [CrossRef]

56. Freitas, F.A.d.S.; Vasconcelos, F.F.X.; Peixoto, S.A.; Hassan, M.M.; Dewan, M.A.A.; Albuquerque, V.H.C.D.; Filho, P.P.R. IoT System for School Dropout Prediction Using Machine Learning Techniques Based on Socioeconomic Data. Electronics 2020, 9 , 1613. [CrossRef]

57. Villegas-Ch, W.; Román-Cañizares, M.; Palacios-Pacheco, X. Improvement of an Online Education Model with the Integration of Machine Learning and Data Analysis in an LMS. Appl. Sci. 2020, 10, 5371. [CrossRef]

58. Villegas-Ch, W.; Arias-Navarrete, A.; Palacios-Pacheco, X. Proposal of an Architecture for the Integration of a Chatbot with Artificial Intelligence in a Smart Campus for the Improvement of Learning. Sustainability 2020, 12, 1500. [CrossRef]

59. Han, Z.; Xu, A. Ecological evolution path of smart education platform based on deep learning and image detection. Microprocess. Microsyst. 2021, 80, 103343. [CrossRef]

60. Shi, D.; Wang, T.; Xing, H.; Xu, H. A learning path recommendation model based on a multidimensional knowledge graph framework for e-learning. Knowl.-Based Syst. 2020, 195, 105618. [CrossRef]

61. Chang, M.; D’Aniello, G.; Gaeta, M.; Orciuoli, F.; Sampson, D.; Simonelli, C. Building Ontology-Driven Tutoring Models for Intelligent Tutoring Systems Using Data Mining. IEEE Access 2020, 8, 48151-48162. [CrossRef]

62. Rajkumar, R.; Ganapathy, V. Bio-Inspiring Learning Style Chatbot Inventory Using Brain Computing Interface to Increase the Efficiency of E-Learning. IEEE Access 2020, 8, 67377-67395. [CrossRef]

63. Ruangvanich, S.; Nilsook, P.; Wannapiroon, P. System Architecture of Learning Analytics in Intelligent Virtual Learning Environment. IJEEEE Int. J. e-Educ. e-Bus. e-Manag. e-Learn. 2019, 9, 90-99. [CrossRef]

64. Barlybayev, A.; Kaderkeyeva, Z.; Bekmanova, G.; Sharipbay, A.; Omarbekova, A.; Altynbek, S. Intelligent System for Evaluating the Level of Formation of Professional Competencies of Students. IEEE Access 2020, 8, 58829-58835. [CrossRef]

65. Leithardt, V.R.Q.; Rolim, C.; Rosseto, A.; Geyer, C.; Dantas, M.A.R.; Silva, J.S.; Nunes, D. Percontrol: A pervasive system for educational environments. In Proceedings of the 2012 International Conference on Computing, Networking and Communications (ICNC), Maui, HI, USA, 30 January-2 February 2012; pp. 131-136. [CrossRef]

66. Lin, J.; Li, Y.; Lian, J. A novel recommendation system via L0-regularized convex optimization. Neural Comput. Appl. 2020, 32, 1649-1663. [CrossRef]

67. Chen, Y.; Zheng, Q.; Ji, S.; Tian, F.; Zhu, H.; Liu, M. Identifying at-risk students based on the phased prediction model. Knowl. Inf. Syst. 2020, 62, 987-1003. [CrossRef]

68. Niknam, M.; Thulasiraman, P. LPR: A bio-inspired intelligent learning path recommendation system based on meaningful learning theory. Educ. Inf. Technol. 2020, 25, 3797-3819. [CrossRef]

69. Turabieh, H.; Azwari, S.A.; Rokaya, M.; Alosaimi, W.; Alharbi, A.; Alhakami, W.; Alnfiai, M. Enhanced Harris Hawks optimization as a feature selection for the prediction of student performance. Computing 2021, 103, 1417-1438. [CrossRef]

70. Iatrellis, O.; Savvas, I.K.; Fitsilis, P.; Gerogiannis, V.C. A two-phase machine learning approach for predicting student outcomes. Educ. Inf. Technol. 2021, 26, 69-88. [CrossRef]

71. Ullah, F.; Wang, J.; Farhan, M.; Jabbar, S.; Naseer, M.K.; Asif, M. LSA Based Smart Assessment Methodology for SDN Infrastructure in IoT Environment. Int. J. Parallel Program. 2020, 48, 162-177. [CrossRef]

72. Nuguri, S.S.; Calyam, P.; Oruche, R.; Gulhane, A.; Valluripally, S.; Stichter, J.; He, Z. vSocial: A cloud-based system for social virtual reality learning environment applications in special education. Multimed. Tools Appl. 2021, 80, 16827-16856. [CrossRef]

73. Azzi, I.; Jeghal, A.; Radouane, A.; Yahyaouy, A.; Tairi, H. A robust classification to predict learning styles in adaptive E-learning systems. Educ. Inf. Technol. 2020, 25, 437-448. [CrossRef]

74. Mendes, A.S.; Silva, L.A.; Blas, H.S.S.; de La Iglesia, D.H.; Encinas, F.G.; Leithardt, V.R.Q.; González, G.V. Physical Movement Helps Learning: Teaching Using Tracking Objects with Depth Camera. In Trends and Applications in Information Systems and Technologies; Rocha, Á.; Adeli, H., Dzemyda, G., Moreira, F., Ramalho Correia, A.M., Eds.; Springer International Publishing: Cham, Switzerland, 2021; pp. 183-193._18. [CrossRef]

75. Saccol, A.Z.; Barbosa, J.L.V.; Schlemmer, E.; Reinhard, N. Mobile Learning in Organizations: Lessons Learned from Two Case Studies. Int. J. Inf. Commun. Technol. Educ. (IJICTE) 2011, 7, 11-24. [CrossRef] 
76. Barbosa, J.L.V.; Hahn, R.; Barbosa, D.N.F.; Segatto, W. Intensive use of mobile technologies in a computer engineering course. Comput. Appl. Eng. Educ. 2014, 22, 686-698. [CrossRef]

77. Klein, A.Z.; da Silva Freitas, J.C., Jr.; Mattiello da Silva, J.V.V.M.; Barbosa, J.L.V.; Baldasso, L. The Educational Affordances of Mobile Instant Messaging MIM: Results of Whatsapp ${ }^{\circledR}$ Used in Higher Education. Int. J. Distance Educ. Technol. 2018, 16, 51-64. [CrossRef]

78. Barbosa, J.L.V.; Hahn, R.M.; Barbosa, D.N.F.; Saccol, A.I.d.C.Z. A ubiquitous learning model focused on learner interaction. Int. J. Learn. Technol. 2011, 6, 62-83. [CrossRef]

79. Barbosa, J.L.V.; Barbosa, D.N.F.; de Oliveira, J.M.; Rabello, S.A., Jr. A Decentralized Infrastructure for Ubiquitous Learning Environments. J. Univers. Comput. Sci. 2014, 20, 1649-1669. [CrossRef]

80. Cárdenas-Robledo, L.A.; Peña-Ayala, A. Ubiquitous learning: A systematic review. Telemat. Inform. 2018, 35, 1097-1132. [CrossRef]

81. Ferreira, L.G.; Barbosa, J.L.V.; Gluz, J.C.; Matter, V.K.; Barbosa, D.N.F. Using Learner Group Profiles for Content Recommendation in Ubiquitous Environments. Int. J. Inf. Commun. Technol. Educ. (IJICTE) 2020, 16, 1-19. [CrossRef]

82. da Silva, L.G.; Neto, E.G.d.A.; Francisco, R.; Barbosa, J.L.V.; Silva, L.A.; Leithardt, V.R.Q. ULearnEnglish: An Open Ubiquitous System for Assisting in Learning English Vocabulary. Electronics 2021, 10, 1692. [CrossRef]

83. Rosa, J.H.; Barbosa, J.L.V.; Kich, M.; Brito, L. A Multi-Temporal Context-aware System for Competences Management. Int. J. Artif. Intell. Educ. 2015, 25, 455-492. [CrossRef]

84. Martini, B.G.; Helfer, G.A.; Barbosa, J.L.V.; Espinosa Modolo, R.C.; da Silva, M.R.; de Figueiredo, R.M.; Mendes, A.S.; Silva, L.A.; Leithardt, V.R.Q. IndoorPlant: A Model for Intelligent Services in Indoor Agriculture Based on Context Histories. Sensors 2021, 21, 1631. [CrossRef] [PubMed]

85. Aranda, J.A.S.; Bavaresco, R.S.; de Carvalho, J.V.; Yamin, A.C.; Tavares, M.C.; Barbosa, J.L.V. A computational model for adaptive recording of vital signs through context histories. J. Ambient. Intell. Humaniz. Comput. 2021, 1-15. [CrossRef]

86. Barbosa, J.; Tavares, J.; Cardoso, I.; Alves, B.; Martini, B. TrailCare: An indoor and outdoor Context-aware system to assist wheelchair users. Int. J.-Hum.-Comput. Stud. 2018, 116, 1-14. [CrossRef]

87. Barbosa, J.L.V.; Martins, C.; Franco, L.K.; Barbosa, D.N.F. TrailTrade: A model for trail-aware commerce support. Comput. Ind. 2016, 80, 43-53. [CrossRef]

88. Wagner, A.; Barbosa, J.L.V.; Barbosa, D.N.F. A model for profile management applied to ubiquitous learning environments. Expert Syst. Appl. 2014, 41, 2023-2034. [CrossRef]

89. Rosa, J.H.d.; Barbosa, J.L.; Ribeiro, G.D. ORACON: An adaptive model for context prediction. Expert Syst. Appl. 2016, 45, 56-70. [CrossRef]

90. Dupont, D.; Barbosa, J.L.V.; Alves, B.M. CHSPAM: A multi-domain model for sequential pattern discovery and monitoring in contexts histories. Pattern Anal. Appl. 2020, 23, 725-734. [CrossRef]

91. Filippetto, A.S.; Lima, R.; Barbosa, J.L.V. A risk prediction model for software project management based on similarity analysis of context histories. Inf. Softw. Technol. 2021, 131, 106497. [CrossRef] 